\title{
Physicality and Usability Guidelines to Overcome the Interaction Complexities
}

\author{
Mahmood Ashraf ${ }^{1 *}$, Rabia Shakir', Mohammad Abrar ${ }^{2}$, Muhammad Tahir ${ }^{3}$ and Thabit Sabbah ${ }^{4}$ \\ 'Department of Computer Science, Federal Urdu University of Arts, Science and Technology, Islamabad, Pakistan; \\ mahmood@fuuastisb.edu.pk, rabi.khan91288@yahoo.com \\ 2Department of Computer Science, Bache Khan University, Charade, KPK, Pakistan; \\ abrar@bkuc.edu.pk \\ ${ }^{3}$ Faculty of Computing and Information Technology, University of Jeddah, Saudi Arabia; \\ mtyousaf@uj.edu.sa, \\ ${ }^{4}$ Faculty of Technology and Applied Sciences, Al-Quads Open University, Ramallah, Palestine; \\ tazazmeh@qou.edu
}

\begin{abstract}
Objectives: To develop the physicality and usability guidelines to reduce the interaction complexities and the cognitive burden on the users. Methods/Statistical Analysis: The study is conducted on the kitchen appliances. Three case studies were conducted on different kitchen appliances. Forty to fifty participants were selected from different age group, qualification, and cities. The data were collected from the participant on the bases of pretest and posttest questionnaire and direct observation method. The study was divided into two phases i.e. formulation of guidelines and comparative analysis. The study I and study II were used for guideline formulation and study III provided a comparative analysis. The qualitative research paradigms were employed for data analysis. Findings: Based on the data analysis, the new guidelines were proposed and evaluated in terms of physicality principles and usability components. Subsequently, t-test was used to validate, evaluate, and compare the results against ISO and IEC. This research has showed that the proposed physicality and usability guidelines are helpful in overcoming interaction complexities, reducing cognitive burden, and saving time. Application/Improvements: The data analysis showed that the proposed guidelines will improve the user experience by $94 \%$ and $85 \%$ in the physicality and usability of the kitchen appliances, respectively. The proposed guidelines can be employed in improving the design of these appliances to overcome interaction complexities.
\end{abstract}

Keywords: Human Computer Interaction, Interaction Complexities, Kitchen Appliances, Physicality Component, Usability Component

\section{Introduction}

The world has become a globe of modern techniques and electronics. In the era of technology, kitchen appliances are taking their place in technical world $1 \underline{1}$ Kitchen appliances are consequently contributing as a primarily social purpose ${ }^{2}$. Moreover, they are playing a paramount role in mundane life. Due to technological enhancement, the look and feel of everything has been changed. Modern kitchen appliances with technological aspects are best example ${ }^{3}$. There are a huge number of domestic appliances that provide convenience in cooking and other kitchen related tasks. These types of kitchen appliances are frequently used in restaurants, hotels as well

${ }^{*}$ Author for correspondence 
as homes ${ }^{4}$. Recent domestic appliances are incorporated with electronics and provide outstanding features such as reduction in cost, reliability, efficiency with the help of embedded sensors and microcontrollers ${ }^{5,6}$. The design of appliance has a great impact on its usage. Smart kitchen appliances are intelligent and provides touch interface. These appliances make life easier as well as provide convenience to the user ${ }^{1}$. User can give input by touching the surface of appliance. Due to less physical interaction, smart appliances increase cognitive burden on user ${ }^{6}$.

Physical kitchen appliances have turned their face

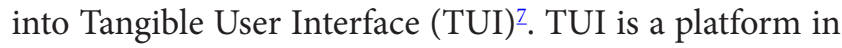
which user collaborate with the system through physical controls. It focuses on designing the interaction with itself and exploits the richness of bodily movement ${ }^{8}$. Some of the kitchen appliances uses Embedded System (ES) or implanted appliances. ES is a device in which electrical and mechanical functions can be planted in terms of real time constrictions. ES are precise, specific, and indivisible while their parts are integrated with each other to provide features and concurrent functionalities ${ }^{-12}$. The first interaction between user and the device takes place through their physical interface i.e. touch system, buttons, or sliders ${ }^{13}$. Physicality, the branch of Human Computer Interaction (HCI), is the next user interface breakthrough in which appliances with electrical and physical buttons have turned into embedded systems ${ }^{14}$. Physicality illustrates the consequences of features related to the physical interfaces and provides explanations regarding embodiment $\frac{10-17}{}$. Physicality relates with the commitment and involvement of human and the system interface during interaction $\frac{10,18}{}$. It revisited the bodily interaction with the help of mechanical and physical interface and provides intellect communication capabilities ${ }^{\underline{19}}$. Usability, on the other hand, defines that how much an interactive system is simple, trouble free, effortless, and pleasant in use ${ }^{3}$. Physicality and Usability works side by side but developers mostly focus on usability and neglect physicality. Usability applies to all aspects of a product or a system with which users might interact ${ }^{9}$. The upcoming appliances acquires fascinating design features not only in terms of their physical appearance like shape, buttons, size but also they provide embedded software digital interface like functions and menus that provides amusement to user ${ }^{15}$. The experimental and observational research paradigms were selected for conducting a comparative analysis of six different kitchen appliances.

Physical things are those which have some material existence and perceived through senses. Physicality is the characteristic of a physical thing which refers to items that that can be gripped. The researcher provides the intangible perceptive of physicality with cooperative design and finally concluded that physicality plays an important role in cooperative design. The researcher discussed two levels of physicality; first defined the type of work and the collective practice of collaborators. He carried out an experiment on student designers and asked them to design a system. The students developed a software interface. They highlighted that physicality is projected as in the ubiquitous strategies in the near future. The researcher concluded that physicality is an important factor that can be neglected in cooperative design. It has many other aspects that cannot be easily extracted through voice or touch ${ }^{20}$.

Some studies showed that it is obvious that embedded systems are playing the paramount role in routine life. During interaction, users are minute, intellectual and immediate responders. According to the research it is clear that embedded system developers are demanding to augment the complications for the users while the software developers are trying to diminish the complexity due to their design. In their research, the physicality principles have been described for each physical control. The researcher investigated the interaction intricacies in implanted system ${ }^{13}$. In another study the researchers recruited 16 users for assessments of two microwave cookers manufactured by the same company; one of them comprises of dial layout while other interface includes buttons. They presented the assumption that comprises of four components. The participants were well-versed about 
the representative tasks. The performance of product conducted through a group of people rather than comparison between performances of individual users. The participants were also allowed to stop their task whenever they want and all their measurements would also be removed on their demand. They analyzed that the results were according to their predictions about hypothesis. But there were also some noteworthy differences such as time completion of a task with dial interface and button interface. A variety of errors also occurred in button interface. The reason of error is large number of same type of buttons made the users confused. The users who are young can perform the tasks efficiently due to their learning proficiency. It is also determined that generation gap also matters. Aged users spend more time than youngsters. It is also suggested that the complexity of interface include multiple factors, only buttons is not the cause of complexity 21 .

Embedded systems are going on increasing day by day. They investigated the complexities found in embedded systems and the main objective of the research was to develop a physicality framework to tame the complexities of embedded systems ${ }^{6}$. The physicality aspects were studied and highlighted that it can be neglected in mundane life devices. The ES developers are increasing complexities and physical interaction due to their small size and Embeddedness and in the result they create cognitive burden on user's mind. There are 23 numbers of participants that perform experiment on the given devices ${ }^{10}$.

The researchers introduce an intellectual cuisine supportive structure that facilitates consumer with collective, interdependent, automatic, and perceptive support for cooking. The structure enhances ordinary and familiar kitchen domestic devices with extensive assortments of perceptions. The interface of appliance was hooked and interdependent inwardly to assume the existing condition in the cuisine procedure and also offer elegant directions. The focus of the research is to provide the method in terms of dispensation and the interpretative abilities required to direct a chef in the course of procedure ${ }^{22}$. The next sections provide a detailed description of all three user studies conducted in the course of this research.

\section{User Study I}

\subsection{Introduction}

The first experimental and observational study was planned with the objective to evaluate the physicality aspects and usability components of kitchen appliances. The study was conducted to inspect and observe that how much the user feel convenience while operating the appliances. The main focus of the study was to find the hurdles during interaction with the appliance. The study included analysis of the data collected by the user during performing desired tasks and filling of posttest questionnaire. The kitchen appliances selected for the evaluation were oven and toaster.

\subsection{Design}

A pre-test questionnaire included the consent of participants and their demographic details. Pre-test questionnaire includes name, occupation, age and gender of the participants. The tasks were normal to avoid the cognitive burden on user. A post-test questionnaire was designed based on four physicality principles (exposed state, hidden state, tangible transitions, and bounce back $)^{13}$. It also included five usability components learnability, efficiency, memorability, error, and satisfaction ${ }^{23}$.

\subsection{Participants and Procedure}

Forty (40) participants were involved in this user study. All the participants were volunteers. The targeted users were segregated into two equally portions such that $50 \%$ male and $50 \%$ female. The study was primarily conducted at kitchen and wherever the users were available at their suitable positions. Participants were observed carefully while they are performing representative tasks. When the participants acknowledged about completion of tasks, they were presented with the post-test questionnaire. 


\subsection{Data Analysis}

Four questions were based on physicality principles and rest of six includes concepts of usability components.
Likert-scale values evaluated against each physicality principle and usability component discussed in study according to the total number of users. Table 1 shows the

Table 1. Result analysis for toaster

\begin{tabular}{|c|c|c|c|c|c|c|}
\hline \multirow[b]{2}{*}{ S No } & \multirow[b]{2}{*}{ Questions } & \multicolumn{5}{|c|}{ Toaster } \\
\hline & & $\begin{array}{l}\text { Strongly } \\
\text { disagree }\end{array}$ & Disagree & Neutral & Agree & $\begin{array}{c}\text { Strongly } \\
\text { Agree }\end{array}$ \\
\hline & \multicolumn{6}{|c|}{ Physicality principles } \\
\hline 1 & $\begin{array}{l}\text { The Button is showing its internal } \\
\text { function? } \\
\text { This feature is helpful to operate the } \\
\text { device? }\end{array}$ & 3 & 3 & 6 & 17 & 11 \\
\hline 2 & $\begin{array}{l}\text { The control offers feeling of bumps. Do } \\
\text { you Think it is easy to rotate the dial? }\end{array}$ & 0 & 1 & 4 & 16 & 19 \\
\hline 3 & $\begin{array}{l}\text { The control returns back to its original } \\
\text { state after some time. Do you think it } \\
\text { is helpful to know the current status of } \\
\text { device? }\end{array}$ & 0 & 0 & 11 & 21 & 8 \\
\hline \multirow[t]{2}{*}{4} & $\begin{array}{l}\text { When dial is moving backward gradually } \\
\text { by showing its progress it is easier to know } \\
\text { the progress of device than digital display? }\end{array}$ & 1 & 7 & 19 & 9 & 4 \\
\hline & \multicolumn{6}{|c|}{ Usability components } \\
\hline 5 & $\begin{array}{l}\text { It is easy for you to accomplish basic task } \\
\text { first time when you use the device? }\end{array}$ & 5 & 5 & 6 & 21 & 3 \\
\hline 6 & Do you able to use the control quickly? & 3 & 4 & 11 & 16 & 6 \\
\hline 7 & $\begin{array}{l}\text { It is easy to remember how to use the } \\
\text { device second time. }\end{array}$ & 0 & 1 & 4 & 15 & 20 \\
\hline 8 & $\begin{array}{c}\text { Do you feel the device the device is } \\
\text { pleasant to use? }\end{array}$ & 1 & 2 & 14 & 18 & 5 \\
\hline 9 & $\begin{array}{l}\text { Have you faced any trouble while } \\
\text { performing the task? }\end{array}$ & 4 & 14 & 14 & 6 & 2 \\
\hline 10 & $\begin{array}{l}\text { How easy it is for you to recover from } \\
\text { them? }\end{array}$ & 0 & 2 & 6 & 22 & 10 \\
\hline
\end{tabular}


Table 2. Result analysis for oven

\begin{tabular}{|c|c|c|c|c|c|c|}
\hline \multirow[b]{2}{*}{ S No } & \multirow[b]{2}{*}{ Questions } & \multicolumn{5}{|c|}{ Oven } \\
\hline & & $\begin{array}{l}\text { Strongly } \\
\text { disagree }\end{array}$ & Disagree & Neutral & Agree & $\begin{array}{l}\text { Strongly } \\
\text { Agree }\end{array}$ \\
\hline \multicolumn{7}{|c|}{ Physicality Components } \\
\hline 1 & $\begin{array}{l}\text { The button is showing its internal function? } \\
\text { This feature is helpful to operate the device? }\end{array}$ & 0 & 1 & 4 & 18 & 17 \\
\hline 2 & $\begin{array}{l}\text { The control offers feeling of bumps. Do you } \\
\text { Think it is easy to rotate the dial? }\end{array}$ & 1 & 4 & 1 & 18 & 16 \\
\hline 3 & $\begin{array}{l}\text { The control returns back to its original state } \\
\text { after some time. } \\
\text { Do you think it is helpful to know the current } \\
\text { status of device? }\end{array}$ & 0 & 1 & 3 & 25 & 11 \\
\hline 4 & $\begin{array}{l}\text { When dial is moving backward gradually by } \\
\text { showing its progress it is easier to know the } \\
\text { progress of device than digital display? }\end{array}$ & 5 & 5 & 13 & 10 & 7 \\
\hline \multicolumn{7}{|c|}{ Usability Components } \\
\hline 5 & $\begin{array}{l}\text { It is easy for you to accomplish basic task first } \\
\text { time when you use the device? }\end{array}$ & 1 & 3 & 11 & 17 & 8 \\
\hline 6 & Do you able to use the control quickly? & 0 & 3 & 7 & 23 & 7 \\
\hline 7 & $\begin{array}{l}\text { It is easy to remember how to use the device } \\
\text { second time. }\end{array}$ & 2 & 1 & 2 & 12 & 23 \\
\hline 8 & $\begin{array}{l}\text { Do you feel the device the device is pleasant } \\
\text { to use? }\end{array}$ & 0 & 2 & 12 & 23 & 3 \\
\hline 9 & $\begin{array}{l}\text { Have you faced any trouble while performing } \\
\text { the task? }\end{array}$ & 12 & 13 & 7 & 8 & 0 \\
\hline 10 & How easy it is for you to recover from them? & 0 & 2 & 9 & 16 & 13 \\
\hline
\end{tabular}




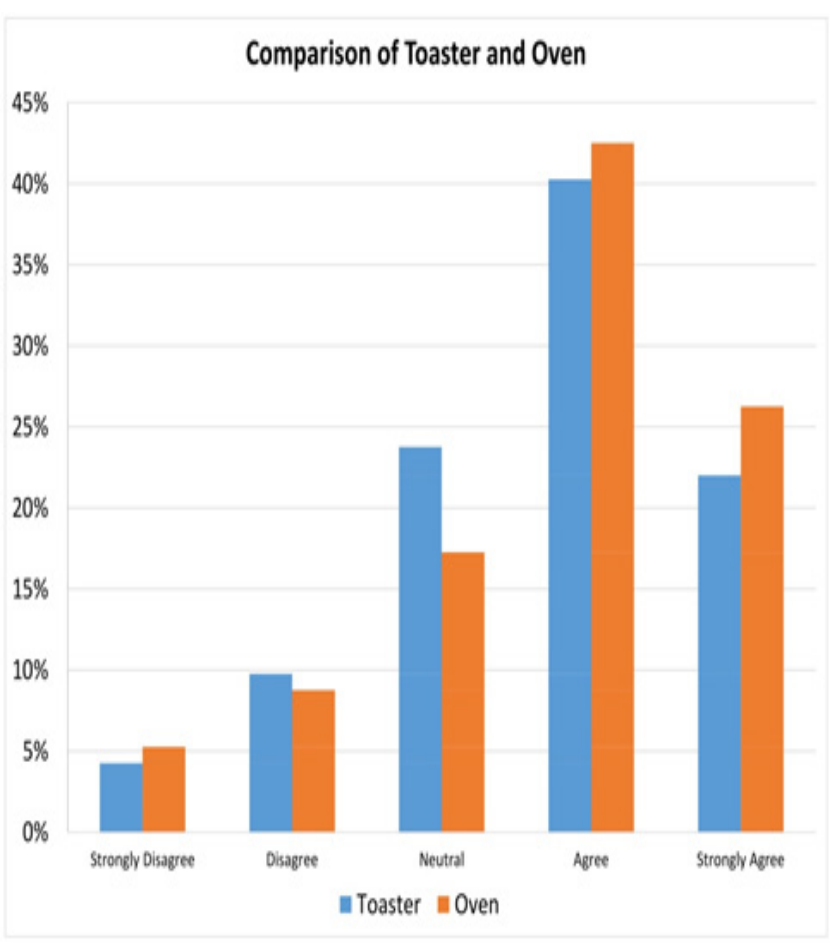

Figure 1. Comparison of toaster and oven.

summary of the questionnaire used in user study I.The study associated with the toaster showed that the participants selected "Agree" (43\%) from Likert-scale in most of the cases.On the other hand $15 \%$ of the responses were "Neutral", 28\% for "Strongly Agree", and 7\% for "Strongly Disagree" and 7\% for "Disagree". In the analysis of oven, again some tasks assigned to user that was based on physicality principles and usability components. Later on, Likert-scale values analyzed according to each question. On the basis of these questions, average and percentage were calculated. The questions were same as asked for toaster but the representative tasks are different. The summary is shown in Table 2.

The results of oven showed that the participants selected "Agree" (45\%) from Likert-scale in most of the cases. However, $10 \%$ of the responses were "Neutral", $43 \%$ for Strongly Agree, 0\% for Strongly Disagree and 2\% for Disagree. Figure 1 provides the comparison on both appliances.

\subsection{Comparison and Result}

After compiling the results analysis of both appliances, the comparison between them has been made. The aver-

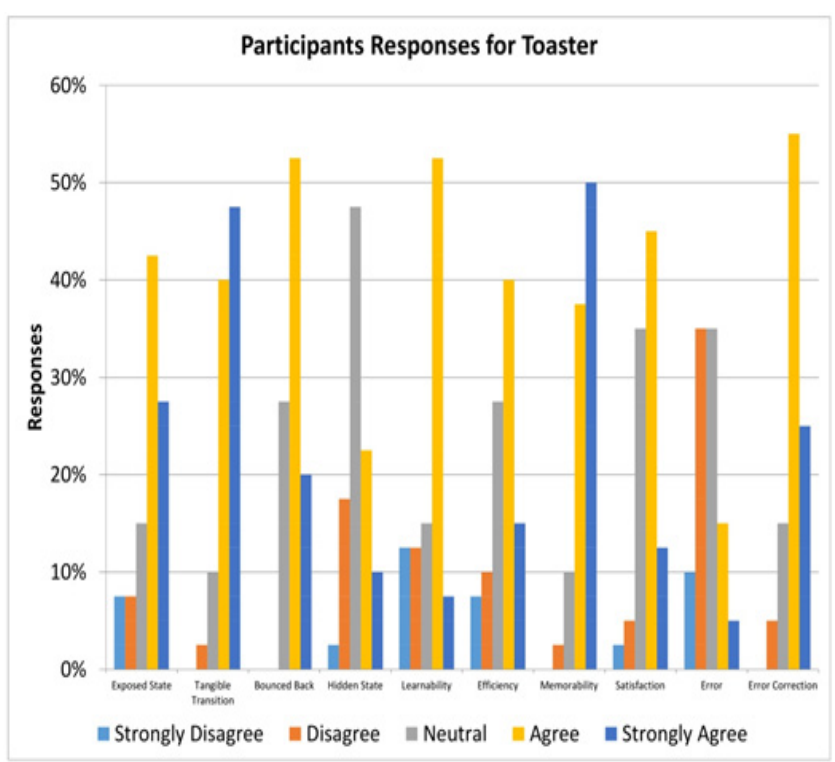

Figure 2. Responses of participants for each physicality principle and usability component for toaster.

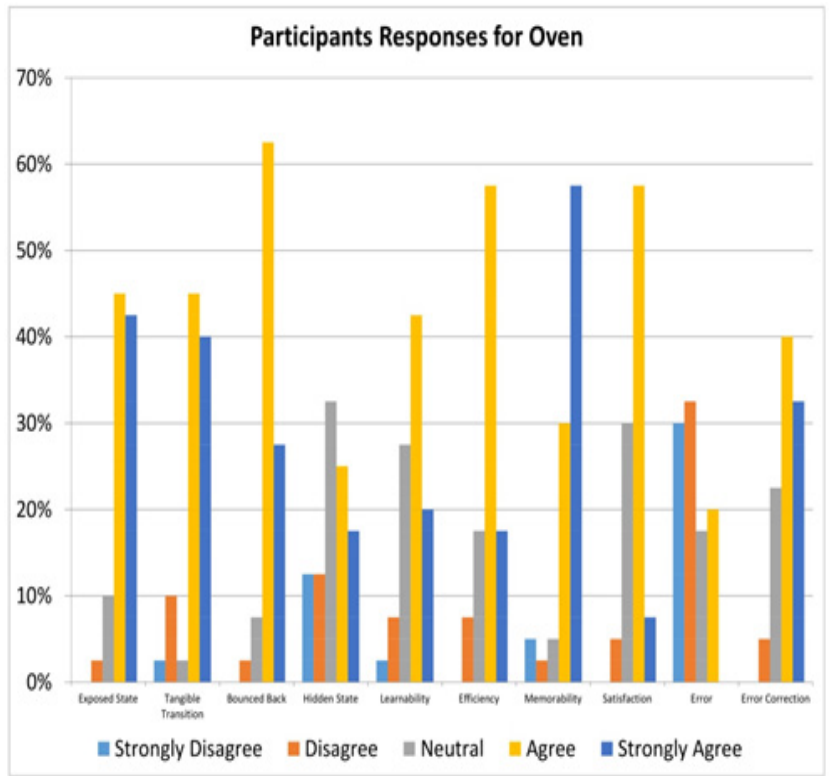

Figure 3. Responses of participants for each physicality principle and usability component for oven. 
age results inclined towards "Agree" for oven. The results of toaster are slightly different from oven.Physicality principles and usability components evaluated for both the appliances. The results for toaster after the evaluation of physicality principles and usability tend towards "Agree". The results are shown in Figure 2. The result for oven after the evaluation of physicality principles and usability alsoinclined towards "Agree" but it is slightly different from "Strongly Agree". The results are shown in Figure 3.

\subsection{Findings}

Although the result analysis showed that appliances have been designed according to user's approach but there is a gap between their satisfaction and usage level. The gap draws the user's attention towards betterment and improvement in the appliance design.

\subsection{Interaction Complexities with respect to Physicality Principles and Usability Components}

There are some observations that were examined during the trial. These observations describe the feelings of user during interaction with appliance regarding each physicality principal and usability component. The remarks will play a paramount role towards the improvement of the upcoming appliances Table 3.

\subsection{Proposed Guidelines}

After the detailed discussion and result analysis, the new guidelines have been proposed in the light of observations. The guidelines are provided in Table 4.

Table 3. Interaction complexities (oven and toaster)

\begin{tabular}{|c|c|c|}
\hline S No & Principle /Component & Interaction complexity \\
\hline 1 & Exposed state & Trouble to on and off \\
\hline 2 & Hidden state & Lack of user's perception \\
\hline 3 & Compliant Interaction & Time complexity \\
\hline 4 & Tangible transition & Trouble in per-heat \\
\hline 5 & Learnability & Complex structure \\
\hline 6 & Learnability & Cognitive burden due to limited control \\
\hline 7 & Efficiency & Easy for familiar while complicated for \\
& Memorable & Unfamiliar \\
\hline 9 & Satisfaction & Confusion during interaction \\
\hline
\end{tabular}


Table 4. Proposed guidelines (oven and toaster)

\begin{tabular}{|c|c|c|}
\hline S No & $\begin{array}{l}\text { Principle / } \\
\text { Component }\end{array}$ & Proposed Guideline \\
\hline 1 & Exposed state & There should be a proper button for on and off \\
\hline 2 & Hidden state & $\begin{array}{l}\text { The instruction on the device should be written } \\
\text { properly }\end{array}$ \\
\hline 3 & $\begin{array}{l}\text { Compliant } \\
\text { Interaction }\end{array}$ & $\begin{array}{l}\text { The control must possess the property of } \\
\text { exposing its time. }\end{array}$ \\
\hline 4 & Tangible transition & $\begin{array}{l}\text { There should be instruction for operating the } \\
\text { device must be written around the control }\end{array}$ \\
\hline 5 & Learnability & $\begin{array}{l}\text { The structure of appliance should be self- } \\
\text { illustrative }\end{array}$ \\
\hline 6 & Learnability & $\begin{array}{c}\text { The control on the appliance should be an } \\
\text { adequate in order to overcome Cognitive } \\
\text { burden. }\end{array}$ \\
\hline 7 & Efficiency & The design of an appliance must be simple \\
\hline 8 & Memorable & The control should be labeled \\
\hline 9 & Satisfaction & $\begin{array}{c}\text { The device should be rich by all means like } \\
\text { numbers of labeled control, functionality and } \\
\text { their structure }\end{array}$ \\
\hline
\end{tabular}

\section{User Study II}

\subsection{Introduction}

A comparative study was planned with the objective to appraise physicality principles and usability components on both appliances. The selected kitchen appliances are most commonly used in mundane life. The study was intended to compare the user's response regarding both appliances. The functionalities of the appliances were same but their structure was different. The main focus of the study is to analyze that which appliance is better for user regarding their structure. The study includes analysis of data collected by the use during performing representative tasks and filling of post test questionnaires. The kitchen appliances used for evaluation are juicer blender and chopper.

\subsection{Design}

A pre-test questionnaire (Annex-I) includes the consent of participants and their demographic details. Pre-test questionnaire includes name, occupation, Age 
and Gender of the participant. The tasks were normal to avoid the cognitive burden on user. A post-test questionnaire was designed based on four physicality principles (exposed state, hidden state, tangible transitions, bounce back) discussed by author in ${ }^{13}$. It also includes five usability components (learnability, efficiency, memorability, error and satisfaction) developed by Jackob Nielson $\underline{29}$.

\subsection{Participants and Procedure}

There were forty participants included in this user study. All the participants were volunteers. The targeted users were segregated into two equally portions of male and female. None of the forty participants were familiar with physicality principles and usability components. The study was mainly conducted in kitchen. However, some users were approached at their convenient locations. Participants observed through their facial expressions during performing tasks. Some participants captured from behind by their approval. When the participants acknowledged about completion of tasks, they were presented with the post-test questionnaire.

\subsection{Data Analysis}

Three questions were based on physicality principles and rest of five includes concepts of usability components. Likert-scale values evaluated against each physicality principle and usability component discussed in study according to the total number of users. Subsequently average and percentage can also be calculated in Table

Table 5. Result analysis for juicer blender

\begin{tabular}{|c|c|c|c|c|c|}
\hline \multirow[b]{2}{*}{ S No } & \multirow[b]{2}{*}{ Questions } & \multicolumn{4}{|c|}{ Juicer blender } \\
\hline & & $\begin{array}{l}\text { Principle/ } \\
\text { component }\end{array}$ & Yes & Neutral & No \\
\hline & \multicolumn{5}{|c|}{ Physicality Principles } \\
\hline 1 & Is the button showing its internal state? & Exposed state & 10 & 17 & 13 \\
\hline 2 & $\begin{array}{l}\text { Is there any control showed feeling of bumps? Is it } \\
\text { helpful to operate the device? }\end{array}$ & $\begin{array}{l}\text { Tangible } \\
\text { transition }\end{array}$ & 2 & 9 & 29 \\
\hline \multirow[t]{2}{*}{3} & $\begin{array}{l}\text { Whether the device showed its current sate when } \\
\text { you press the button? }\end{array}$ & Bounced back & 34 & 5 & 1 \\
\hline & \multicolumn{5}{|c|}{ Usability Component } \\
\hline 4 & Is it easy to use the device first time? & Learnability & 13 & 14 & 3 \\
\hline 5 & Do you able to use the device quickly? & Efficiency & 8 & 17 & 15 \\
\hline 6 & Is it pleasant to use? & Satisfaction & 9 & 22 & 9 \\
\hline 7 & $\begin{array}{c}\text { Will you remember how to use the device next } \\
\text { time? }\end{array}$ & Memorable & 37 & 3 & 0 \\
\hline
\end{tabular}


Table 5 Continued

\begin{tabular}{|c|c|c|c|c|c|}
\hline \multirow{2}{*}{ S No } & \multicolumn{2}{|c|}{ Questions } & \multicolumn{3}{|c|}{ Juicer blender } \\
\cline { 3 - 6 } & & $\begin{array}{c}\text { Principle/ } \\
\text { component }\end{array}$ & Yes & Neutral & No \\
\hline \multirow{2}{*}{8} & $\begin{array}{c}\text { Have you faced any trouble while performing } \\
\text { the tasks? If yes, how much it is easy for you to } \\
\text { recover from them? }\end{array}$ & Error Control & 21 & 12 & 7 \\
\hline 9 & Are you satisfied with the device? & Satisfaction & 11 & 20 & 9 \\
\hline
\end{tabular}

Table 6. Result analysis for chopper

\begin{tabular}{|c|c|c|c|c|c|}
\hline \multirow{2}{*}{ S No } & \multirow{2}{*}{ Questions } & \multicolumn{4}{|c|}{ Chopper } \\
\hline & & $\begin{array}{l}\text { Principle/ } \\
\text { component }\end{array}$ & Yes & Neutral & No \\
\hline & \multicolumn{5}{|c|}{ Physicality Principles } \\
\hline 1 & Is the button showing its internal state? & Exposed state & 7 & 12 & 21 \\
\hline 2 & $\begin{array}{l}\text { Is there any control showed feeling of bumps? Is it } \\
\text { helpful to operate the device? }\end{array}$ & $\begin{array}{l}\text { Tangible } \\
\text { transition }\end{array}$ & 20 & 16 & 4 \\
\hline \multirow[t]{2}{*}{3} & $\begin{array}{l}\text { Whether the device showed its current sate when } \\
\text { you press the button? }\end{array}$ & Bounced back & 36 & 2 & 2 \\
\hline & \multicolumn{5}{|c|}{ Usability Component } \\
\hline 4 & Is it easy to use the device first time? & Learnability & 6 & 15 & 19 \\
\hline 5 & Do you able to use the device quickly? & Efficiency & 5 & 12 & 23 \\
\hline 6 & Is it pleasant to use? & Satisfaction & 7 & 20 & 13 \\
\hline 7 & $\begin{array}{l}\text { Will you remember how to use the device next } \\
\text { time? }\end{array}$ & Memorable & 33 & 6 & 1 \\
\hline 8 & $\begin{array}{l}\text { Have you faced any trouble while performing } \\
\text { the tasks? If yes, how much it is easy for you to } \\
\text { recover from them? }\end{array}$ & Error Control & 29 & 8 & 3 \\
\hline
\end{tabular}


5. The average results showed that $16.11(40 \%)$ participants were agreed on "Yes" while 13.22 (33\%) showed their responses as "Neutral". There are only 10.67 (27\%) of the participants exhibited "No" observations. The average values have also been calculated for further analysis of results.

As the study was comparative, for the analysis of appliance II again some tasks assigned to the user. Some of the tasks for appliance II were different from the appliance I. The tasks were of moderate nature while the questions were based on three physicality principles and five usability components. Later on, Likert-scale values have been analyzed according to each question. On the basis of these questions, average and percentage have been calculated. The responses according to questions are shown in Table 6. The average results showed that 16.44 (41\%) participants were agreed on "Yes"while 13.44 (34\%) showed their responses as "Neutral". There are only 10.11 (25\%) of the participants exhibited "No" observations.

\subsection{Comparison and Analysis}

After compiling the results analysis of both appliances, the comparison between them has been made. The average results inclined towards "Yes" for both appliances. The

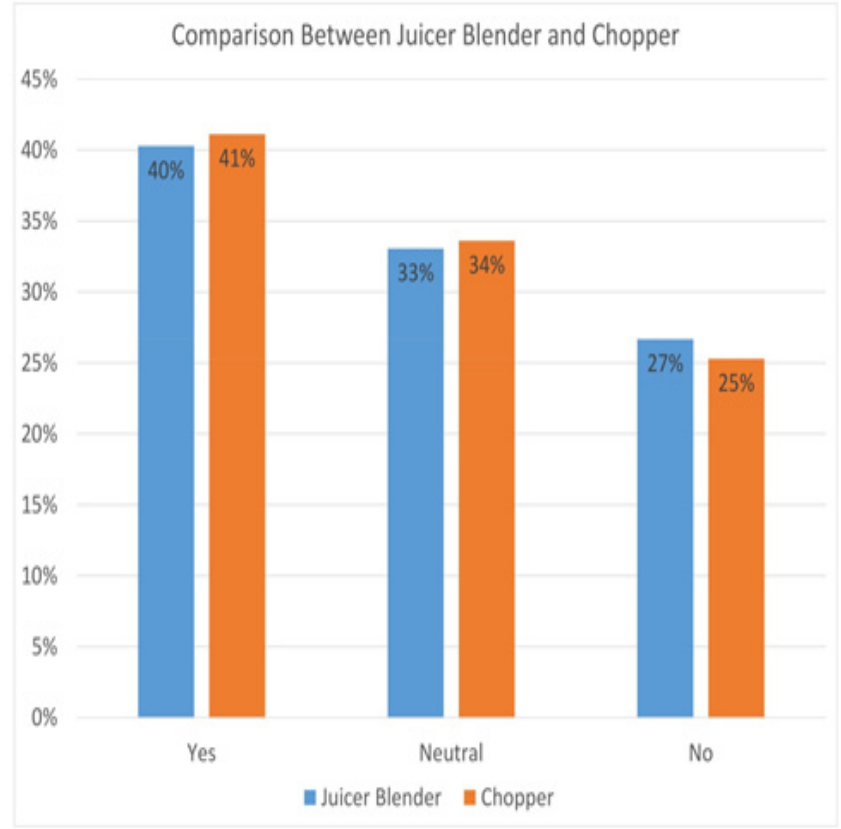

Figure 4. Comparison of juicer blender and chopper.

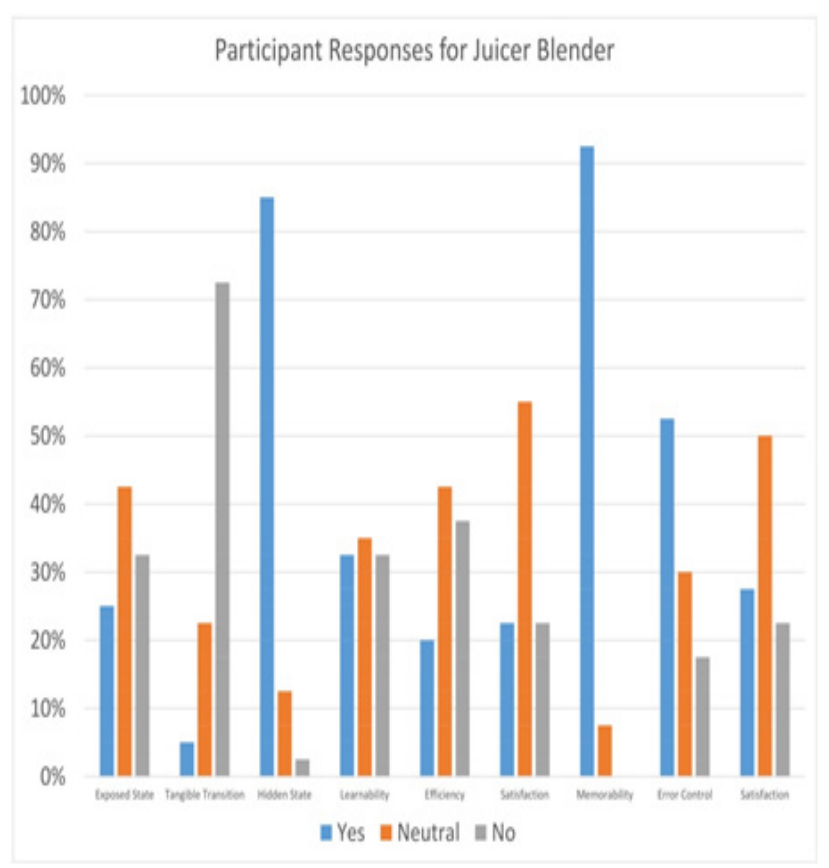

Figure 5. Responses of participants for each physicality principle and usability component for juicer blender.

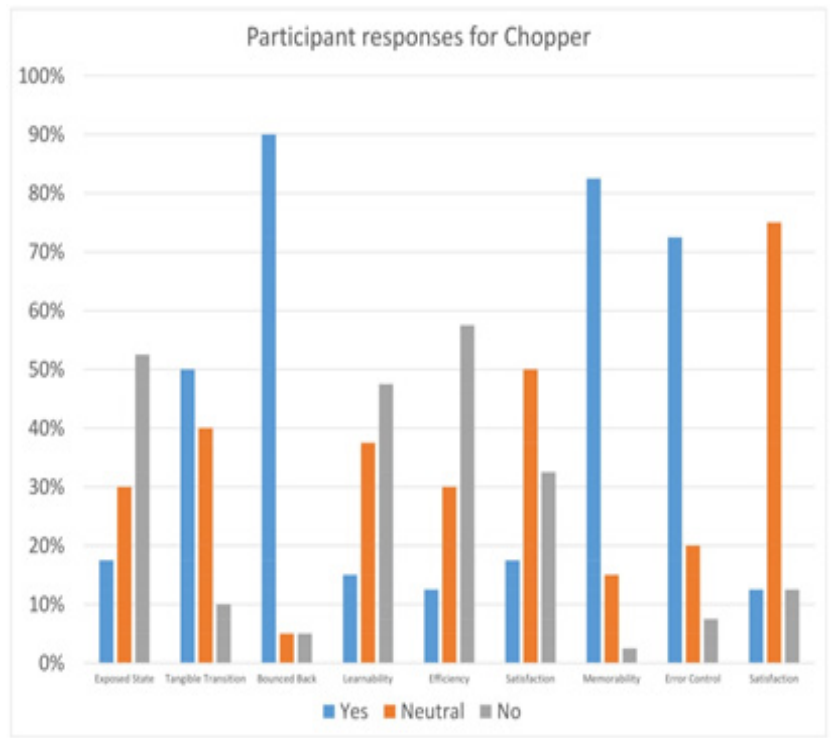

Figure 6. Responses of participants for each physicality principle and usability component for chopper

results of appliance II are slightly greater than appliance II. The combine results are depicted in Figure 4.

Physicality principles and usability components are evaluated for both appliances. There were Nine (09) questions in which four (04) were based on physicality 
principles while rest of five (05) were based on usability components. The results showed that appliance I, after the evaluation of physicality principles and usability tends towards "Yes" as well as "Neutral". The results are shown in Figure 5. The participant are either satisfied with the appliances or neutral with its overall functionalities. While there is small number of participant with negative impact of the physicality principles i.e., Tangible transition.

The results for appliance II after the evaluation of physicality principles and usability also inclined towards "Yes". The results are shown in Figure 6.

\subsection{Findings}

The result analysis showed that both the appliances have been designed according to user's approach but there is a gap between their satisfaction and usage level. The appliance I consist of only one control while appliance II is rich in physicality principle than appliance I. Although appliance I is simple but there were some flaws in it while appliance II is complex but it still gather more positive results than appliance I. The gap draws the user's attention towards betterment and improvement in the appliance design.

\subsection{Interaction Complexities w.r.t Physicality Principle and Usability Components}

The focus of the study is to evaluate the overall design and functionality of the appliances according to physicality principles and usability components. The study is experimental as well as observational. The issues regard-

Table 7. Interaction complexities for juicer blender and chopper

\begin{tabular}{|c|c|c|}
\hline S No & Principle component & Proposed guidelines \\
\hline 1 & Exposed State & $\begin{array}{l}\text { There must have physicality aspects for on and } \\
\text { off button. }\end{array}$ \\
\hline 2 & Hidden Transition & $\begin{array}{l}\text { There should be no hidden functionalities and } \\
\text { controls in the appliance. }\end{array}$ \\
\hline 3 & Tangible Transition & $\begin{array}{l}\text { The surface of the dimmer should not be } \\
\text { smooth. }\end{array}$ \\
\hline 4 & Bounced Back & $\begin{array}{l}\text { There should be a proper indication about the } \\
\text { current status of the control on the appliance. }\end{array}$ \\
\hline 5 & Learnability & $\begin{array}{l}\text { The functionalities should be properly } \\
\text { fabricated. }\end{array}$ \\
\hline 6 & Learnability & $\begin{array}{l}\text { The interface of the device should be } \\
\text { comprehensible and accessible. }\end{array}$ \\
\hline 7 & Efficiency & The design of the appliance must be simple. \\
\hline 8 & Memorability & The controls should be labeled. \\
\hline 9 & Satisfaction & The appliance should be straightforward. \\
\hline
\end{tabular}


ing appliances encountered during experiment have been analyzed. In the light of these issues the guidelines have been made. The improvements are required for designing appliance to reduce interaction complexities. The users get confused in a variety of ways. They felt cognitive burden, confusion, depression and trouble while performing initial tasks. The reason is lack of desired and unlabeled controls and limited instructions written on the device in some cases. However, there are some observations that examined during the trial Table 7.

\subsection{Proposed Guidelines}

After the detailed discussion and result analysis, some guidelines have been made. Some of the guidelines were similar while some of them were different according to observation. The proposed guideline is highlighted in Table 8 based on these findings.

\section{User Study III}

\subsection{Introduction}

A relative study was planned with the aim to evaluate the guidelines proposed in User Study I and User Study II. For this purpose two kitchen appliances have been selected. Design guidelines according to physicality principles and usability components have been applied on these appliances. The selected kitchen appliances are most commonly used in everyday life. The study was intended to compare the user's response regarding both appliances. The functionalities of the appliances were same but their structure was different. The main focus of the study is to analyze that which appliance is better for user regarding their structure. The study includes analysis of data collected by the user during performing representative tasks

Table 8. Proposed guidelines for juicer blender and chopper

\begin{tabular}{|c|c|c|}
\hline S No & Principle component & Proposed guidelines \\
\hline 1 & Exposed State & Complication while switching on/off. \\
\hline 2 & Hidden Transition & Status of the appliance was unrecognizable. \\
\hline 3 & Tangible Transition & Difficulty while rotating the dial. \\
\hline 4 & Bounced Back & Improper indication while pressing the \\
\hline 5 & Learnability & Complicated functionalities. \\
\hline 6 & Learnability & Cognitive burden due to limited control. \\
\hline 7 & Efficiency & Lack of user's performance. \\
\hline 8 & Memorability & Unlabeled controls. \\
\hline 9 & Satisfaction & Confusion during interaction. \\
\hline
\end{tabular}


and filling of post test questionnaires. The kitchen appliances used for evaluation are fryers.

\subsection{Design}

A pre-test questionnaire (Annex-I) includes the consent of participants and their demographic details. Pre-test questionnaire includes name, occupation, age and gender of the participant. The tasks were normal to avoid the cognitive burden on user. A post-test questionnaire was designed based on four physicality principles exposed state, compliant interaction, hidden state and tangible transition discussed by author in ${ }^{13}$. It also includes five usability components (learnability, efficiency, memorability, error and satisfaction) developed by Jackob Nielson ${ }^{29}$.
The questionnaire was designed on the basis of design guidelines that were proposed in previous studies.

\subsection{Participants and Procedure}

There were fifty participants included in this user study. All the participants were volunteers. The targeted users were segregated into two equally proportions of male and female. Two of the fifty participants were familiar with physicality principles and usability components.

\subsection{Data Analysis}

Four questions were based on physicality principles and rest of five includes concepts of usability components.

Table 9. Result analysis for appliance I (fryer)

\begin{tabular}{|c|c|c|c|c|}
\hline \multirow[b]{2}{*}{ S No } & \multirow[b]{2}{*}{ Questions } & \multicolumn{3}{|c|}{ Appliance 1 (Fryer) } \\
\hline & & $\begin{array}{l}\text { Principle / } \\
\text { component }\end{array}$ & Yes & No \\
\hline & \multicolumn{4}{|c|}{ Physicality Principles } \\
\hline 1 & Is there a button for on and off? & Exposed state & 8 & 42 \\
\hline 2 & $\begin{array}{l}\text { Is the dimmer showed its time while } \\
\text { coming back to its original state? }\end{array}$ & $\begin{array}{l}\text { Compliant } \\
\text { interaction }\end{array}$ & 29 & 21 \\
\hline 3 & $\begin{array}{l}\text { Are the controls showed its } \\
\text { functionality? }\end{array}$ & Hidden state & 34 & 16 \\
\hline \multirow[t]{2}{*}{4} & Is the dimmer easy to rotate? & $\begin{array}{l}\text { Tangible } \\
\text { transition }\end{array}$ & 38 & 12 \\
\hline & \multicolumn{4}{|c|}{ Usability Components } \\
\hline 5 & $\begin{array}{l}\text { Is the structure of appliance self- } \\
\text { illustrative? }\end{array}$ & Learnability & 11 & 39 \\
\hline 6 & $\begin{array}{l}\text { Are the controls on appliance overcome } \\
\text { cognitive burden while performing the } \\
\text { tasks }\end{array}$ & Learnability & 14 & 36 \\
\hline
\end{tabular}


Table 9 Continued

\begin{tabular}{|c|c|c|c|c|}
\hline \multirow{2}{*}{ S No } & Questions & \multicolumn{2}{|c|}{ Appliance 1 (Fryer) } \\
\cline { 3 - 5 } & & $\begin{array}{c}\text { Principle / } \\
\text { component }\end{array}$ & Yes & No \\
\hline 7 & Is the design simple? & Efficiency & 40 & 10 \\
\hline 8 & Is the appliance easy to use> & Efficiency & 30 & 20 \\
\hline 9 & $\begin{array}{c}\text { Are the controls labeled in order to } \\
\text { remember next time? }\end{array}$ & Memorability & 19 & 31 \\
\hline 10 & Are you satisfied with this device? & Satisfaction & 7 & 21 \\
\hline 11 & $\begin{array}{c}\text { Is it easy to recover from error if error } \\
\text { occurs? }\end{array}$ & Error Control & 29 & 23 \\
\hline
\end{tabular}

Table 10. Result analysis for appliance II (fryer)

\begin{tabular}{|c|c|c|c|c|}
\hline \multirow{2}{*}{ S No } & \multirow{2}{*}{ Questions } & \multicolumn{3}{|c|}{ Appliance II (Fryer) } \\
\hline & & $\begin{array}{l}\text { Principle/ } \\
\text { component }\end{array}$ & Yes & No \\
\hline & \multicolumn{4}{|c|}{ Physicality Principles } \\
\hline 1 & Is there a button for on and off? & Exposed state & 8 & 42 \\
\hline 2 & $\begin{array}{l}\text { Is the dimmer showed its time while } \\
\text { coming back to its original state? }\end{array}$ & $\begin{array}{l}\text { Compliant } \\
\text { interaction }\end{array}$ & 29 & 21 \\
\hline 3 & $\begin{array}{l}\text { Are the controls showed its } \\
\text { functionality? }\end{array}$ & Hidden state & 34 & 16 \\
\hline \multirow[t]{2}{*}{4} & Is the dimmer easy to rotate? & $\begin{array}{l}\text { Tangible } \\
\text { transition }\end{array}$ & 38 & 12 \\
\hline & \multicolumn{4}{|c|}{ Usability Components } \\
\hline 5 & $\begin{array}{c}\text { Is the structure of appliance self- } \\
\text { illustrative? }\end{array}$ & Learnability & 11 & 39 \\
\hline
\end{tabular}


Table 10 Continued

\begin{tabular}{|c|c|c|c|c|}
\hline 6 & $\begin{array}{c}\text { Are the controls on appliance overcome } \\
\text { cognitive burden while performing the } \\
\text { tasks }\end{array}$ & Learnability & 14 & 36 \\
\hline 7 & Is the design simple? & Efficiency & 40 & 10 \\
\hline 8 & Is the appliance easy to use> & Efficiency & 30 & 31 \\
\hline 9 & $\begin{array}{r}\text { Are the controls labeled in order to } \\
\text { remember next time? }\end{array}$ & Memorability & 19 & 43 \\
\hline 10 & $\begin{array}{c}\text { Are you satisfied with this device? } \\
11\end{array}$ & Satisfaction & 7 & 21 \\
\hline
\end{tabular}

Likert-scale values evaluated against each physicality principle and usability component discussed in study according to the total number of users. Subsequently average and percentages are also calculated in Table 9. The average results showed that 23.55 (47\%) of the participants were agreed on "Yes" while 26.45 (53\%) showed their responses against "No". This showed that the percentage of "No" responses against appliance I is greater than responses against "Yes". As the study was comparative, for the analysis of appliance II again some tasks assigned to the user. Some of the tasks for appliance II were different from the appliance I. The tasks were of moderate nature while the questions were based on four physicality principles and five usability components. Later on, Likert-scale values have been analyzed according to each question. On the basis of these questions, average and percentage have been calculated in Table 10. A large number of populations showed their interest in this appliance. The average results showed that 44.45 (89\%) of the participants were agreed on "Yes" while 5.55 only (11\%) of the participants showed their responses against "No".

\subsection{Comparison and Analysis}

This study is based on the evaluation of physicality prin- ciples and usability guidelines evaluation to overcome interaction complexities in kitchen appliances. However, the comparison has been made on the basis of guidelines. After compiling the results analysis of both appliances, finally the comparison between them has been made in

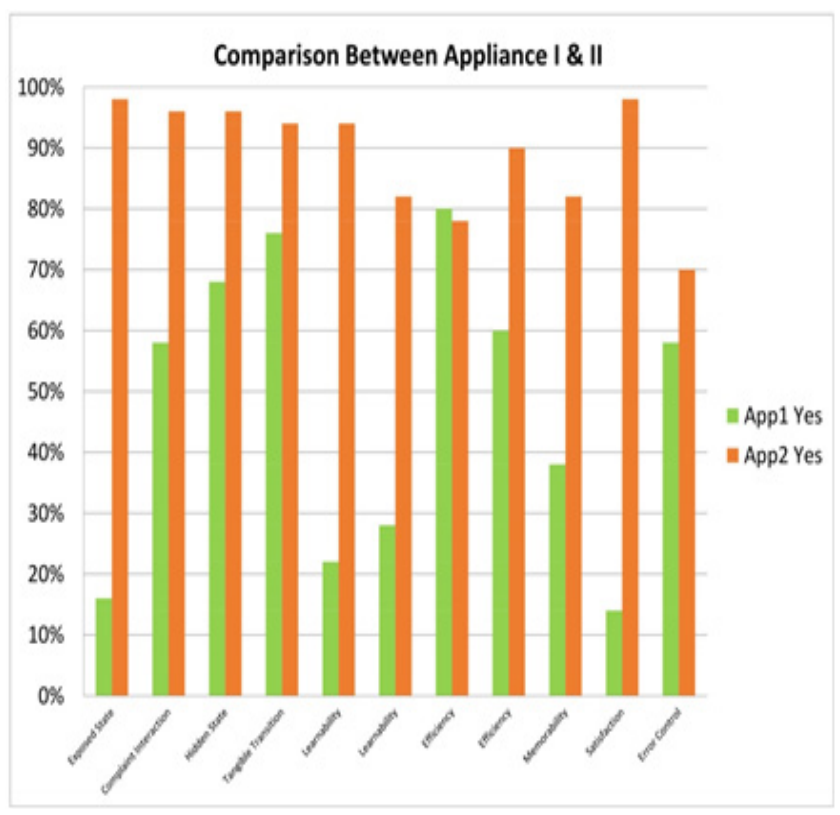

Figure 7. Comparison of appliance I (fryer) and appliance II (fryer). 


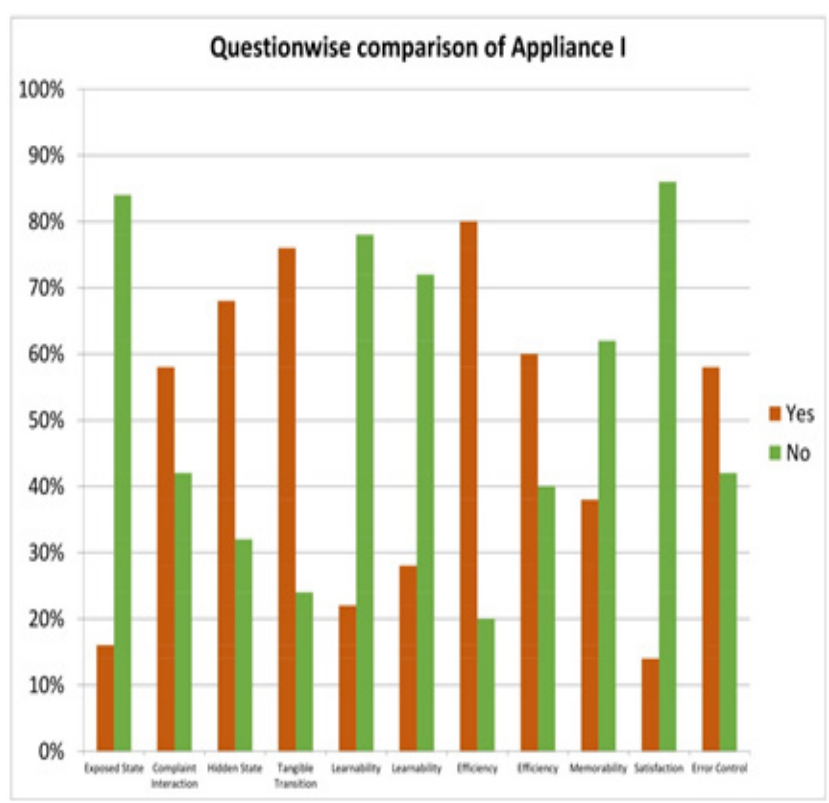

Figure 8. Responses of participants for each physicality principle and usability component for appliance I (fryer).

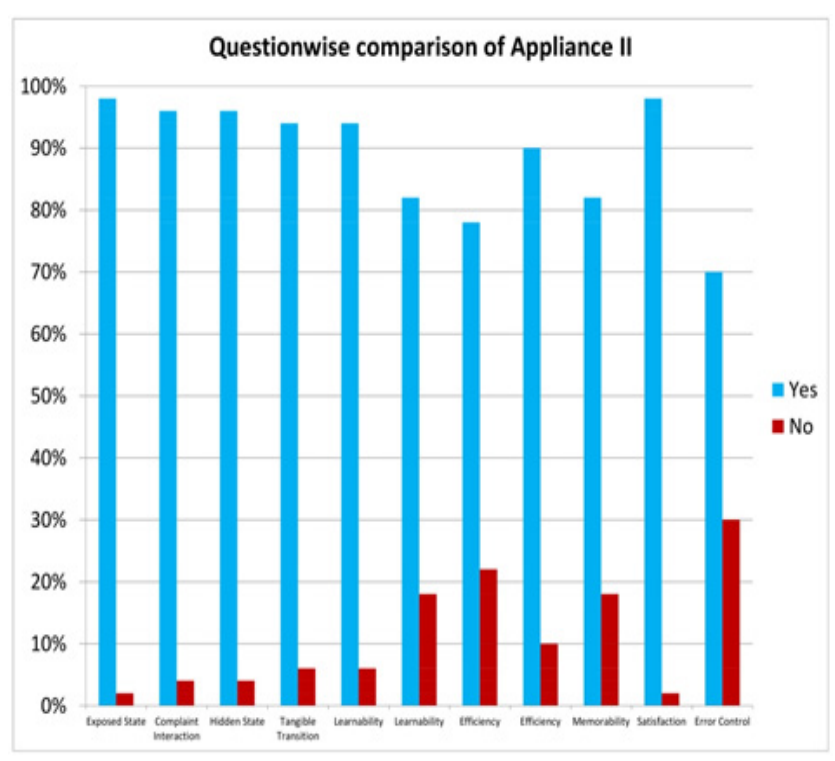

Figure 9. Responses of participants for each physicality Principle and usability component for appliance II (fryer).

Table 11. Result comparison for appliance I (fryer) and appliance II (fryer)

\begin{tabular}{|c|c|c|c|c|c|}
\hline \multirow{2}{*}{ S No } & \multirow{2}{*}{$\begin{array}{c}\text { Principle/ } \\
\text { Component }\end{array}$} & \multicolumn{2}{|c|}{ Appliance I (Fryer) } & \multicolumn{2}{|c|}{ Appliance I (Fryer) } \\
\cline { 3 - 6 } & Yes & No & Yes & No \\
\hline 1 & Exposed state & $16 \%$ & $84 \%$ & $98 \%$ & $2 \%$ \\
\hline 2 & $\begin{array}{c}\text { Compliant } \\
\text { interaction }\end{array}$ & $58 \%$ & $42 \%$ & $96 \%$ & $4 \%$ \\
\hline 3 & Hidden state & $68 \%$ & $32 \%$ & $96 \%$ & $4 \%$ \\
\hline 4 & $\begin{array}{c}\text { Tangible } \\
\text { transition }\end{array}$ & $76 \%$ & $24 \%$ & $94 \%$ & $6 \%$ \\
\hline 5 & Learnability & $22 \%$ & $78 \%$ & $94 \%$ & $6 \%$ \\
\hline 7 & Learnability & $28 \%$ & $72 \%$ & $82 \%$ & $18 \%$ \\
\hline 8 & Efficiency & $80 \%$ & $20 \%$ & $78 \%$ & $22 \%$ \\
\hline 9 & Efficiency & $60 \%$ & $40 \%$ & $90 \%$ & $10 \%$ \\
\hline 10 & Memorability & $38 \%$ & $62 \%$ & $82 \%$ & $18 \%$ \\
\hline 11 & Satisfaction & $14 \%$ & $86 \%$ & $98 \%$ & $2 \%$ \\
\hline & Error Control & $58 \%$ & $42 \%$ & $70 \%$ & $30 \%$ \\
\hline
\end{tabular}


Figure 7. Results can be analyzed in detail which showed that the user's reactions were tending towards "Yes". There were eleven (11) questions in which four (04) of them was based on physicality principles while rest of seven (07) based on usability components. The evaluated results also compared, presented in Table 11. The results for appliance I according to physicality principle and usability components tend towards "No". Participant's Responses for Physicality Principles and Usability Components for Appliance I are shown in Figure 8. The results for appliance II after the evaluation of physicality principles and usability also inclined towards "Yes". The results are shown in Figure 9.

\subsection{Findings}

Although the result analysis showed that both the appliances have been designed according to user's approach but there is a gap between their satisfaction and usage level. The appliance I consist of only one control while appliance II is rich in physicality principle than appliance I. Although appliance I is simple but there were some flaws in it while appliance II is complex but it still gather more positive results than appliance I. The gap draws the user's attention towards betterment and improvement in the appliance design.

\subsection{Guidelines Evaluation}

However, there are some observations that were examined during the trial. These observations describe the feelings of user during interaction with appliance regarding each physicality principle and usability component. The remarks will play a paramount role towards the improvement of the upcoming appliances. The average of "agreed" results also presented in Table xi. The observations were

Table 12. Proposed guidelines for fryer

\begin{tabular}{|c|c|c|c|}
\hline S No & Principle/Component & Proposed Guideline & Agreed \% \\
\hline 1 & Exposed state & $\begin{array}{c}\text { There must have physicality aspect for on } \\
\text { and off button. }\end{array}$ & $98 \%$ \\
\hline 2 & Compliant interaction & $\begin{array}{l}\text { The control must possess the property of } \\
\text { exposing its time. }\end{array}$ & $96 \%$ \\
\hline 3 & Hidden state & $\begin{array}{l}\text { The control must Showed their } \\
\text { Functionality. }\end{array}$ & $96 \%$ \\
\hline 4 & Tangible transition & $\begin{array}{l}\text { The surface of the dimmer should not be } \\
\text { smooth. }\end{array}$ & $94 \%$ \\
\hline 5 & Learnability & $\begin{array}{l}\text { The structure of appliance should be self- } \\
\text { illustrative. }\end{array}$ & $94 \%$ \\
\hline 6 & Learnability & $\begin{array}{l}\text { The control on the appliance should be } \\
\text { adequate in order to overcome cognitive } \\
\text { burden. }\end{array}$ & $82 \%$ \\
\hline 7 & Efficiency & The appliance should be simple to handle. & $78 \%$ \\
\hline
\end{tabular}


Table 12 Continued

\begin{tabular}{|c|c|c|c|}
\hline 8 & Efficiency & The appliance should be easy to use. & $90 \%$ \\
\hline 9 & Memorability & The control should be labeled. & $82 \%$ \\
\hline 10 & Satisfaction & $\begin{array}{r}\text { The device should be rich by all means like } \\
\text { labeled controls, exposed functionality and } \\
\text { simple structure. }\end{array}$ & $98 \%$ \\
\hline 11 & Error Control & $\begin{array}{r}\text { The appliance should be easy to use to } \\
\text { handle in case of error. }\end{array}$ & $70 \%$ \\
\hline
\end{tabular}

based on guidelines to evaluate that whether the proposed guidelines used for betterment or not Table 12 .

\section{8 t-Test Analysis}

The user responses have been statistically analyzed subsequently. Paired sample t-test was applied to the data using SPSS. Appliance II data has been assigned $\mu_{1}$ and appliance I has been assigned $\mu_{2}$. The standard deviation has been calculated. The value of standard deviation was 14.3000 and value of $t$ was derived as $\mathrm{t}=4.849$. The significance value was 0.001 . According to value of $t$ and significance value we reject null hypothesis and hence conclude that the appliance based on proposed guidelines is better than other appliance.

\section{Proposed Design Rules}

Based on the above analysis, this research proposed the following design principle that reduces the limitations of the appliances under the study.

- Appliance should have a proper "On" and "Off" button.

- The instructions on the appliance should be written properly.

- The controls and structure of appliance should be self-illustrative.
- The controls on the appliance should be adequate in order to overcome cognitive burden.

- The design of appliance must be simple so that every user can interact with it effortlessly.

- For the best use of appliance, all the controls should be labeled properly so that user can easily use it next time.

- The controls must possess the property of exposing its time properly.

- The instruction for operating the appliance must be written around the control.

- There should be a proper indication about the current status of the control on the appliance.

- The surface of the dimmer should not be smooth and easy to rotate.

- There should be no hidden functionalities and controls in the appliance.

- The interface of appliance should be straightforward.

- The functionalities should be properly fabricated.

- The interface of the appliance should be comprehensible and accessible.

- The control must possess the property of exposing its time.

- The controls must demonstrate their functionality.

- The appliance should be easy to use. 
- The appliance should be rich by all means like labeled controls, exposed functionality and simple structure.

- The appliance should be easy to handle in case of error.

The design guidelines have been compared with the existing guidelines. The ISO standard for user interface is "ISO 14915 and IEC 61997, ISO 9241 (parts 12-17) and ISO/IEC 9126 (parts 2 and 3)" were focused for comparison. The "ISO 97.040.01 (ISO 3055.1985)" discussed kitchen equipments in general. They conferred the sizes of kitchen equipment and certain appliances. Other standards were also checked but they are beyond of scope. The following four proposed design guidelines have already been addressed in the above stated guidelines:

- The functionalities should be properly fabricated.

- The instructions on the appliance should be written properly.

- The appliance should be rich by all means like labeled controls, exposed functionality and simple structure.

- The interface of the appliance should be comprehensible and accessible.

\section{Conclusion}

The study was embarked to investigate the concept of physicality principles and usability components in designing kitchen appliances in order to overcome interaction complexities. Kitchen appliances are the most common appliances that everyone can use in their mundane life. The need of kitchen appliances is growing day by day. The increasing number of embedded kitchen appliances suggests that kitchen appliances are a gateway towards efficient, simple and easy work. These appliances can play a significant role in performing multiple tasks. The focus of the research is on the subject that how to overcome the interaction complexities in kitchen appliances. Kitchen appliances used in everyday life were evaluated to highlight the interaction complexities. Three user studies were conducted with different intentions mainly to understand the user's interaction with appliances and issues regarding these appliances. Kitchen is a place that can be organized in such a way that every task can be done effectively. This study is set out to investigate the complexities that user encountered during study.

In $1^{\text {st }}$ user study, ordinary kitchen appliances were focused. Two kitchen appliances were evaluated according to physicality principles and usability components. The main focus of the study is to find the interaction complexities encountered during operating the appliance. In this study, four physicality principles and five usability components were evaluated. The study was observational as well as experimental. Both the appliances were independently evaluated according to physicality principles and usability components. The users had "neutral" remarks about efficiency, "strongly agree" for memorability and "disagree" for error component.The rest of the principles and components for both of the appliances have "agreed" responses. The overall average result results was "agree" as well as it was concluded that the appliance II "oven" has more positive responses against appliance I. The observations have been recorded and interaction complexities have been found during experiment. Finally, guidelines have been formulated to overcome the interaction complexities of kitchen appliances. Adaptation of these guidelines while designing kitchen appliances can significantly overcome interaction complexities as well as cognitive burden.

In $2^{\text {nd }}$ user study, again two kitchen appliances were used for evaluation. The study was comparative, experimental as well as observational. Both of the kitchen appliances have some common features but different in terms of manifestation. Four physicality principles and five usability components have been evaluated. Responses were neutral in most of the cases while for some principles and components, responses were yes. Physicality and usability plays a vital role regarding user's satisfaction. The overall result analysis showed that physicality and usability of appliance II is greater than appliance I. In this study, complexities have been uncovered and some guidelines have been in order to get rid of interaction intricacies. User study 3 has been conducted on 
the behalf of user study 1 and two. This study was also comparative, experimental and observational. The guidelines formulated in user study 1 and 2 have been applied on user study 3 . In this study, these guidelines have been evaluated. Two appliances have been used for assessment. Appliance II was according to physicality principles and usability components that were conceived from previous studies. Four physicality principles and five usability components have been addressed. In all of the cases the user responses for appliance II were highly ranked than appliance I. It has been concluded that users feel more satisfaction and convenience during interacting with appliance II that was based on formulated principles. Finally, guidelines have been modified and proposed. The user's responses have been statistically analyzed. Paired sample t-test was applied using SPSS tool. The standard deviation was calculated and significance value has been assessed. It was concluded in $\mathrm{t}$-test that the appliance that was based on guidelines is highly motivated and useful than other appliance. However, the aim of this study was to propose the guidelines that will overcome complexities and cognitive burden from the user. Moreover, it will help in the design of kitchen appliances to provide convenience to the user.Further the proposed design guidelines were also compared with existing guidelines formed by ISO and IEC. It has been observed that four of the proposed guidelines have already been offered in existing guidelines. As the kitchen appliances are the most frequently used appliances in mundane life, therefore the proposed design guidelines will play a paramount role for designing kitchen appliances. The satisfaction level of the user can be elevated which can improve the physicality and usability of kitchen appliances in addition to get rid of cognitive burden.

\section{References}

1. Zallio M, Kelly P, Jakuska M, Rifai H, Berry D. Design of a community-supported capable microwave system for people with intellectual and physical disabilities. In Italian Forum of Ambient Assisted Living; Springer, Cham. 2016. p. $61-78$.
2. Birdja D. The mindful kitchen [Master thesis]. Delft: Faculty of Industrial Design Engineering; 2016.

3. El-Qirem FA, Cockton, G. Dramatic sketches: A new interaction design resource for communicating contextual factors. International Conference on Cross-Cultural Design; Springer, Cham. 2015. p.176-85. Crossref.

4. Kim C, Christiaans $\mathrm{HH}$. The role of design properties and demographic factors in soft usability problems. Design Studies. 2016; 45(1):268-90. Crossref.

5. Buur J, Jensen MV, Djajadiningrat T. Hands-only scenarios and video action walls: novel methods for tangible user interaction design. Proceedings of the 5th Conference on Designing Interactive System Processes, Practices, Methods, and Techniques, ACM; 2004. p. 185-92. Crossref.

6. Ashraf $M$, Ghazali $M$. Investigating physical interaction complexities in embedded systems. IEEE 5th Malaysian Conference in Software Engineering (MySEC); 2011. p. 336-41. Crossref.

7. Israel JH, Hurtienne J, Pohlmeyer AE, Mohs C, Kindsmuller M, Naumann A. On intuitive use, physicality and tangible user interfaces. International Journal of Arts and Technology. 2009; 2(4):348-66. Crossref.

8. Hornecker E. Physicality in tangible interaction: bodies and the world. Physicality 1st International Workshop on Physicality: Position Papers; 2006. p. 21-5.

9. Malinowski A, Yu H. Comparison of embedded system design for industrial applications. IEEE Transactions on Industrial Informatics. 2011; 7(2):244-54. Crossref.

10. Ashraf M, Ghazali M. Physicality quantitative evaluation method. Proceedings of the 25th Australian Computer-Human Interaction Conference: Augmentation, Application, Innovation, Collaboration; 2013. p. 315-24. Crossref.

11. Reddy GR, Blackler A, Mahar D, Popovic V. The effects of cognitive ageing on use of complex interfaces. Proceedings of the 22nd Conference of the Computer-Human Interaction Special Interest Group of Australia on Computer-Human Interaction; 2010. p. 180-3. Crossref.

12. Jozwiak L, Nedjah N, Figueroa M. Modern development methods and tools for embedded reconfigurable systems: A survey. Integration, the VLSI Journal. 2010; 43(1):1-33. Crossref.

13. Ashraf M, Ghazali M. Taming the complexity of embedded system interaction using physicality principles. 3rd Software Engineering Postgraduate Workshop (SEPoW2011); 2011. p. 58-62.

14. Norman DA. The next UI breakthrough, part 2: physicality. Interactions-Designing for Seniors: Innovations for Graying Times. 2013; 14(4):46-7. Crossref. 
15. Hare J, Gill S, Loudon G, Ramduny-Ellis D, Dix A. Physical fidelity: Exploring the importance of physicality on physical-digital conceptual prototyping. Human-Computer Interaction-INTERACT; 2009. p. 217-30.

16. Ghazali M, Dix A. The role of inverse actions in everyday physical interaction. Procceedings of the 2nd International Workshop on Physicality; 2007. p. 21-6.

17. Dix A, Ghazali M, Ramduny-Ellis D. Modelling devices for natural interaction. Electronic Notes in Theoretical Computer Science. 2008; 208:23-40. Crossref.

18. Dix A, Ghazali M, Gill S, Hare J, Ramduny-Ellis D. Physigrams: Modelling devices for natural interaction. Formal Aspects of Computing. 2009; 21(6):613-41. Crossref.

19. Rogers Y, Sharp H, Preece J. Interaction design: Beyond human-computer interaction. John Wiley and Sons; 2011.
20. Vyas D, Heylen D, Nijholt A. Physicality and cooperative design. International Workshop on Machine Learning for Multimodal Interaction; Springer, Berlin, Heidelberg. 2008. p. 325-37. Crossref.

21. Lewis T, Langdon PM, Clarkson PJ. Prior experience of domestic microwave cooker interfaces: A user study. Designing Inclusive Futures. 2008; 95-106. PMid:18776270

22. Neumann A, Elbrechter C, Pfeiffer-Leßmann N, Kõiva R, Carlmeyer B, Rüther S Ritter HJ. Kogni Chef: A Cognitive Cooking Assistant. KI Künstliche Intelligenz. 2017; 31(3):273-81. Crossref.

23. Usability 101: Introduction to usability. Available from: http://www.nngroup.com/articles/usability-101-introduction-to-usability/ 